\title{
TESTING OF CRITICAL FEATURES OF POLYSILICON MEMS
}

\author{
D. A. LaVAN, T. E. BUCHHEIT \\ Sandia National Laboratories, Albuquerque, NM 87185, dalavan@sandia.gov
}

\section{ABSTRACT}

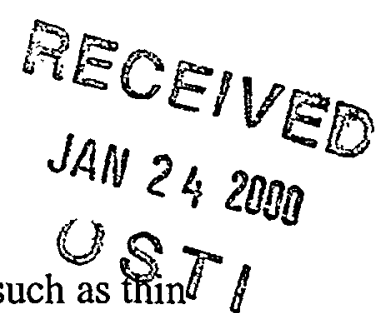

The behavior of MEMS devices is limited by the strength of critical features such as thin ligaments, oxide cuts joining layers, pin joints and hinges. Devices fabricated at Sandia's Microelectronic Development Laboratory have been successfully tested to investigate these features. A series of measurements were performed on samples with gage lengths of 15 to 1000 microns, using conventional and tungsten coated samples as well as samples that include the critical features of standard components in the test section. Specimens have a freely moving pin joint on one end that anchors the sample to the silicon die to allow rotation to reduce effects of bending. Each sample is loaded in uniaxial tension by pulling laterally with a flat tipped diamond in a computer-controlled Nanoindenter. Load is calculated by resolving the measured lateral and normal forces into the applied tensile force and frictional losses. The specimen cross section and gage length dimensions were verified by measuring against a standard in the SEM. Multiple tests can be programmed at one time and performed without operator assistance allowing the collection of significant populations of data.

\section{INTRODUCTION}

Understanding and predicting the reliability of polysilicon micromachined MEMS devices requires a thorough knowledge of the distribution in mechanical properties and the effect of stress concentrating features in these devices. Several authors have published work reflecting different strategies to determine the mechanical properties of polysilicon via beam bending $[1,2]$ and tension testing [3-7]. This project developed a technique that utilizes an automated test machine, capable of testing 20-30 samples per day with little operator involvement and is capable of testing samples on the scale of MEMS devices. The sample design and testing technique is described followed be a description of the data processing procedures.

\section{TECHNIQUE}

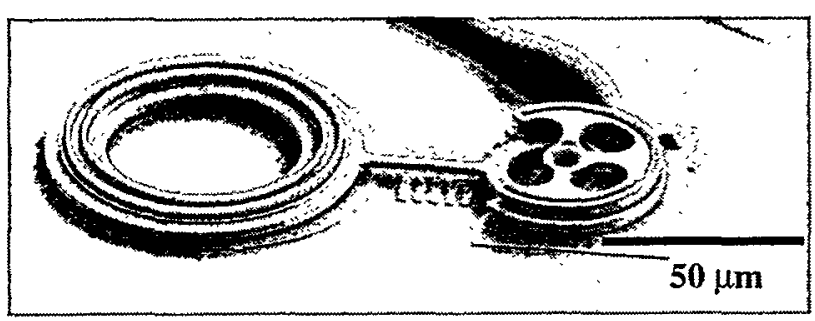

(a)

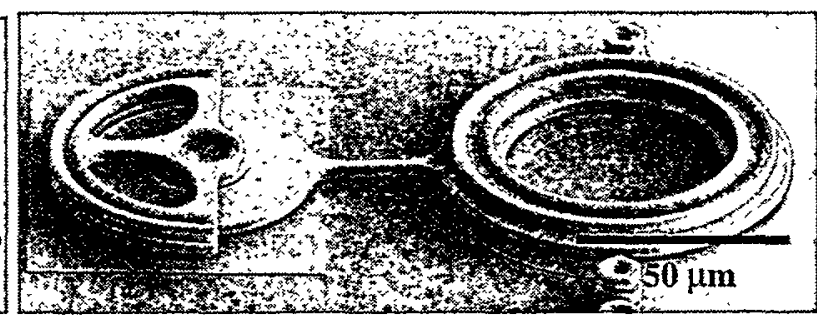

(b)

Figure 1. (a) First generation sample (b) Newest sample design, with a more robust pivot and larger radii in the gage length fillets.

Samples designed to directly measure, under uniform tensile loading, the fracture strength and Young's modulus of polysilicon have been fabricated using Sandia National Laboratories' Ultra-planar Multi-level MEMS Technology (SUMMiT) process. Figure 1 shows two generations of samples after release; the second generation sample, on the right, has a more robust pivot and larger gage-to-ring fillets. The first generation samples tended to fail at regions 


\section{DISCLAIMER}

This report was prepared as an account of work sponsored by an agency of the United States Government. Neither the United States Government nor any agency thereof, nor any of their employees, make any warranty, express or implied, or assumes any legal liability or responsibility for the accuracy, completeness, or usefulness of any information, apparatus, product, or process disclosed, or represents that its use would not infringe privately owned rights. Reference herein to any specific commercial product, process, or service by trade name, trademark, manufacturer, or otherwise does not necessarily constitute or imply its endorsement, recommendation, or favoring by the United States Government or any agency thereof. The views and opinions of authors expressed herein do not necessarily state or reflect those of the United States Government or any agency thereof. 


\section{DISCLAIMER}

Portions of this document may be illegible in electronic image products. Images are produced from the best available original document. 
outside of the gage length; statistical and post-mortem analysis of those samples indicated multiple failure modes with about $20 \%$ breaking in the gage section. Each sample has a freely moving pivot at the fixed end and a pull-ring. The gage section is nominally $2 \mu \mathrm{m}$ wide and 2.5 $\mu \mathrm{m}$ thick. After fabrication, the width is typically $1.8 \mu \mathrm{m}$. The samples are free to rotate about the pivot; the bumpers in the later design limit the range of travel; the samples still have to be aligned in the proper position with a probe tip before testing.

The pull-ring end of a sample is engaged by a $35 \mu \mathrm{m}$ diameter flat-tipped diamond using a nanoindenter. Normal force, lateral force and displacement are recorded. A normal force must be maintained throughout the test to prevent the conical shaped diamond from being pushed upwards by the pull-ring engagement reaction. Once on the surface, the tip moves laterally, which loads the thin polysilicon ligament in tension. The samples and recorded forcedisplacement data are analyzed after testing to calculate the stress-strain response and to identify the sample failure mode.

\section{Data Analysis}

Raw load-displacement data from samples of multiple lengths, shown in Figure 2, is processed in two steps to evaluate the strength and modulus of the material. First, a force balance is solved to correct for the losses due to the frictional sliding of the tip along the substrate. The tip is a flat-bottomed conical diamond with an included angle, $2 \theta$, of $59^{\circ}$. The normal force, $\mathrm{N}$, and lateral force, $\mathrm{L}$, are recorded and must be resolved into the tensile force on the sample, $T$, the reaction due to the tip angle normal to the surface, $N_{r}$, and the frictional losses, $\mathrm{L}_{\mathrm{f}}$ :

$$
\begin{aligned}
& L_{f}=\mu N_{f} \\
& L=T+L_{f} \\
& N=N_{r}+N_{f} \\
& N_{r}=\frac{T}{\tan \theta}
\end{aligned}
$$

The measured displacement must be corrected for machine compliance. The total measured compliance is the sum of the machine compliance (including grips, etc) and the compliance from the tensile gage length. Testing samples with identical cross sectional dimensions and several lengths provides a simple and accurate way to evaluate the machine compliance.

$$
\frac{1}{K_{\text {exp }}}=\frac{1}{K_{\text {machine }}}+\frac{1}{K_{\text {gage }}}
$$

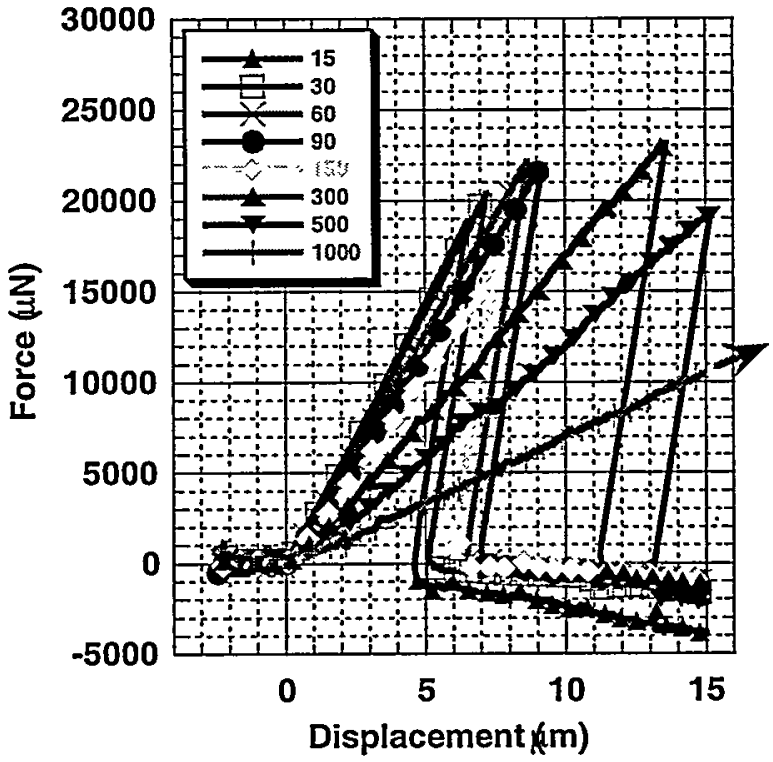

Figure 2. Load-displacement curves from samples with gage lengths of 15 to $1000 \mu \mathrm{m}$ long.

$\mathrm{K}_{\text {machine }}$ is evaluated from the intercept of $1 / \mathrm{K}_{\exp }$ versus sample length. The modulus is determined once $K_{\text {gage }}$ is known for each sample, by dividing the slope of a plot of $K_{\text {gage }}$ versus $1 /$ length by the sample cross sectional area. Linear least squares fit to all the data are used, as 
shown in Figure 3, to minimize the errors due to the individual machine compliance corrections. For small samples, correcting for machine compliance is a large source of error, a negative stiffness was found for some samples.
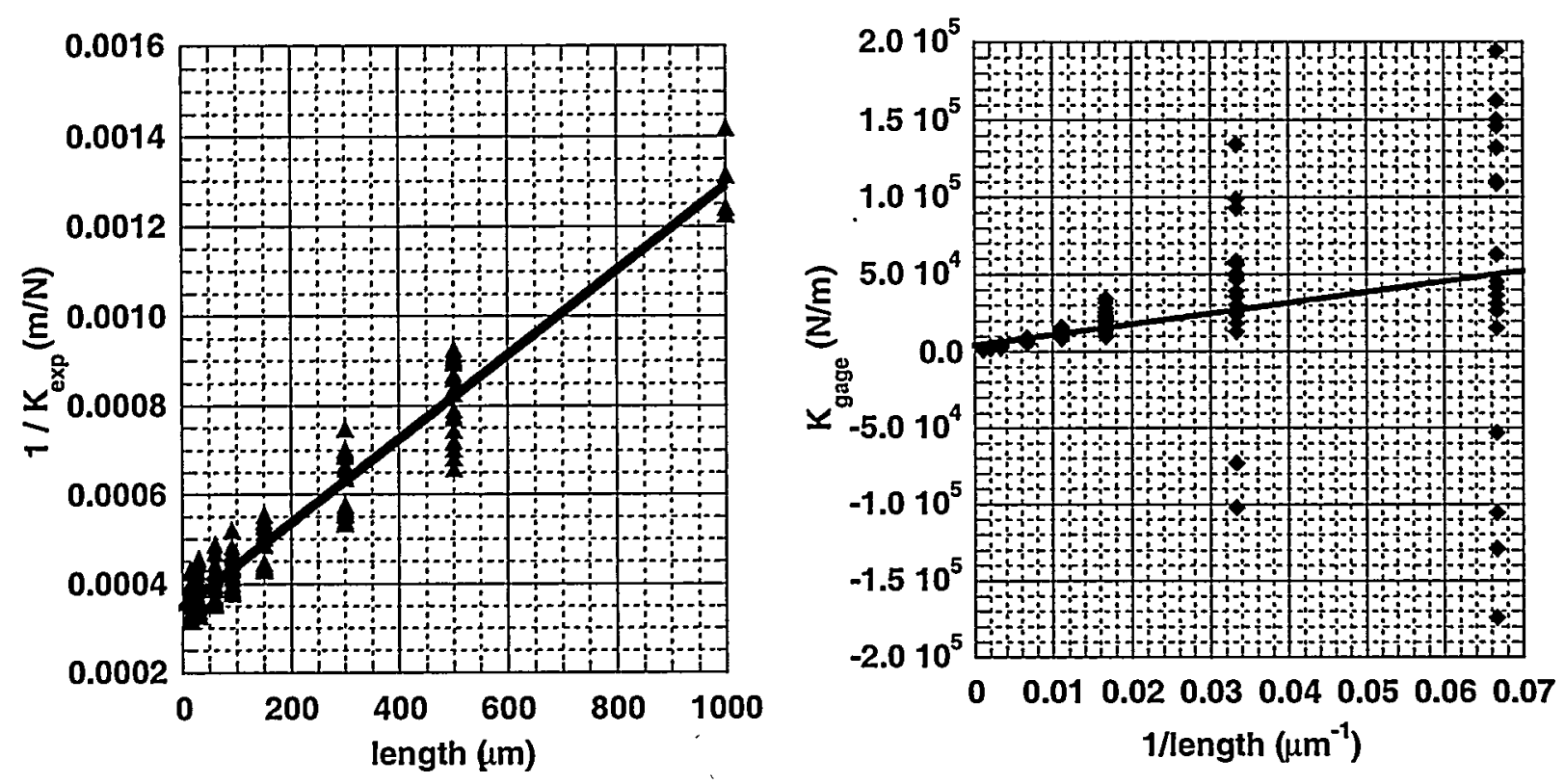

Figure 3. Graphical procedure to calculate modulus (a) $1 / \mathrm{Kexp} v$ length which is evaluated at length $=0$ for $\mathrm{K}_{\text {machine }}$

(b) Slope of $\mathrm{K}_{\text {gage }} \vee 1 /$ length is divided by cross-sectional area to determine modulus.

\section{RESULTS}

\section{Tensile}

Ninety-eight conventionally released samples and fifty tungsten coated samples were tested in tension. The conventionally treated samples were subject to two release process: released and dried by supercritical carbon dioxide or released and coated with a PFTS self assembling monolayer. No difference in strength was found for these samples. Figure 4 shows the strength for each sample plotted as a function of length, surprisingly, no significant decrease was observed as sample size increased. Weibull analysis was performed on the strength data for the conventionally released samples [8]. A probability estimator in the form of $(j-0.5) / n$ was chosen [9]. The Weibull modulus, $\mathrm{m}$, was calculated to be 8.4. Figure 5 shows plots of the strength data for the Weibull analysis.

The mean strength and standard deviation for the conventionally released samples is 4.3 $\pm 0.6 \mathrm{GPa}$. This value drops by $35 \%$ for the tungsten coated samples to $2.8 \pm 0.6 \mathrm{GPa}$. If you consider the minimum strength values obtained for each group, the strength drops from 2.90 to $1.44 \mathrm{GPa}$. Details of the tungsten release process can be found in [10] and its use as an anti-wear coating can be found in [11]. No difference was seen among the modulus values for any of the sample groups; the modulus found from the data in Figure 3 is $170 \mathrm{GPa}$. Texture measurements made on this material [12] show a nearly random distribution of orientations. The theoretical bounds on the polycrystalline modulus are $160-166 \mathrm{GPa}$ [13] considering the Voigt [14] and Reuss [15] models. The relatively large machine compliance, when compared to the sample 
compliance, prevents accurate measurement of the modulus of individual samples, but a reasonable estimate can be made from multiple samples.
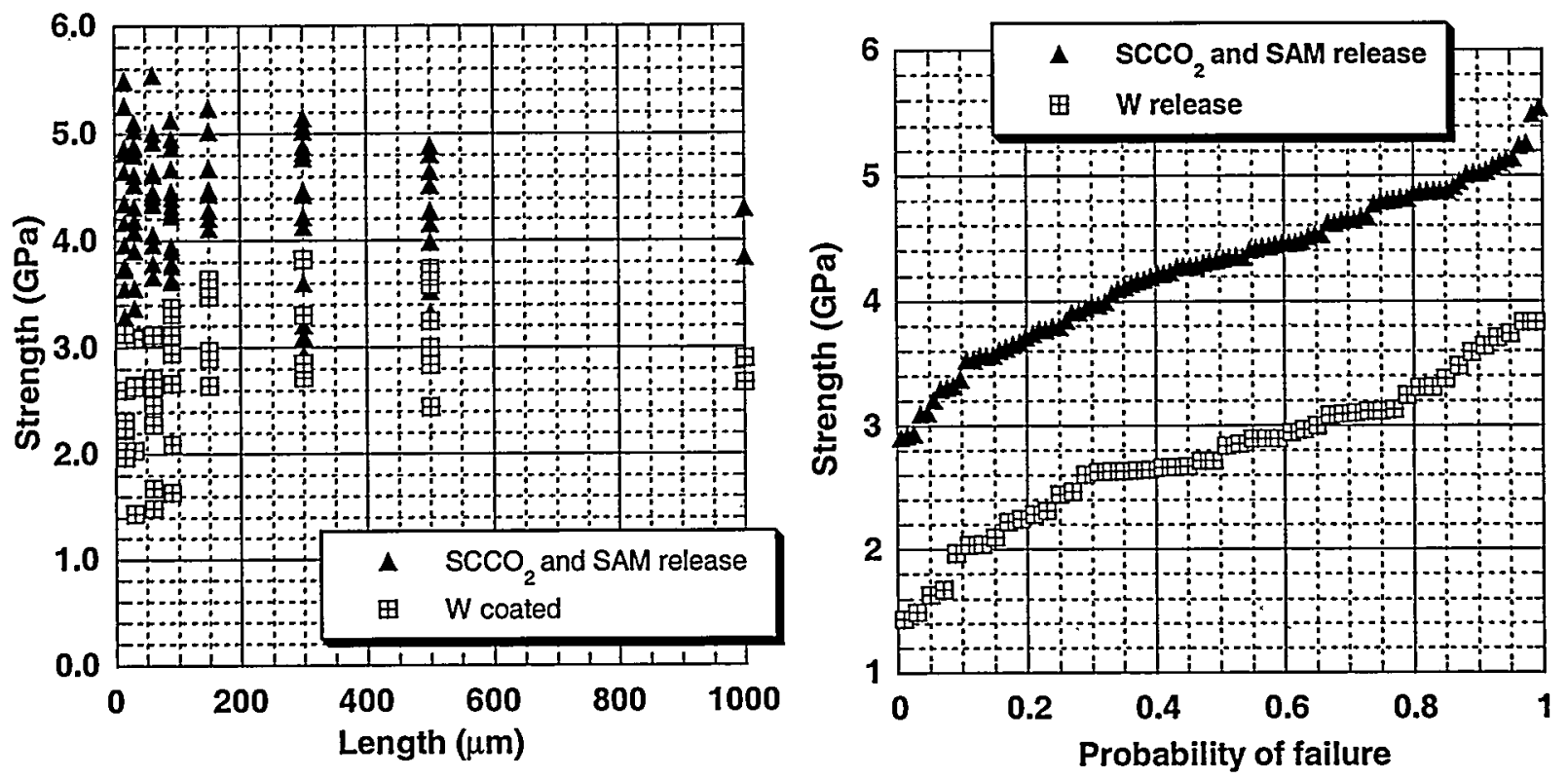

Figure 4. Strength of 98 conventionally released polysilicon samples and 50 tungsten coated samples (a) As a function of length (b) Probability of Failure

\section{TESTING CRITICAL FEATURES}

With an established testing technique, it is simple to incorporate critical features into the gage section of the sample to evaluate the maximum force each structure can endure. Figure 6 depicts a standard hinge that is used in pop-up mirrors. The load displacement curve is not linear for this device because of the complicated geometry, but it was found to fail at approximately 1 $\mathrm{mN}$ force. Other features have been and will continue to be tested to satisfy design and qualification issues.

\section{FRACTURE BEHAVIOR}

Both strength and modulus for polysilicon must be evaluated in relation to fracture toughness and flaw size. The presence of defects can cause a drop in the modulus from that predicted from the elastic constants, however the volume fraction of such flaws has to be a recognizable percentage of the sample volume. Considering that this material has a fracture toughness on the order of 1-3 $\mathrm{MPa} \sqrt{\mathrm{m}}$, flaws approximately $5-20 \mathrm{~nm}$ in size are responsible for initiating fracture [16, 17], which is a very small percentage of the cross section. Figure 7 is a sensitivity plot relating critical stress to flaw size for various values of fracture toughness. Efforts to measure the 
fracture toughness of polysilicon produced at Sandia are underway. Figure 8 shows a classical brittle fracture surface from a tensile sample along with a TEM image of "worm holes" found at the W-polysilicon interface. The size of these flaws is consistent with the equations in the literature that are plotted in Figure 7. Even though the grain size is approaching the size of critical features, the critical flaw size is much smaller than either of these dimensions, and it appears that there is no issue in scaling the fracture analysis.

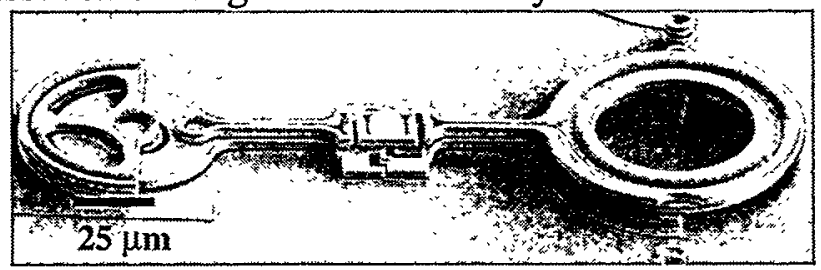

Figure 6. A hinged structure for load testing.

\section{DISCUSSION}

The strength of polysilicon produced at Sandia is higher than that reported from other sources. Direct testing of small samples provides an opportunity to study critical features as well as fracture behavior and failure modes. Further testing is underway to compare the response of other test platforms and compare the results for this material with other direct testing techniques.

\section{ACKNOWLEDGEMENTS}

SEM micrographs were produced by B.B. McKenzie. TEM micrograph provided by T.J. Headley. Sandia is a multiprogram laboratory operated by Sandia Corporation, a Lockheed Martin Company, for the United States Department of Energy under Contract DE-AC04-94AL85000.
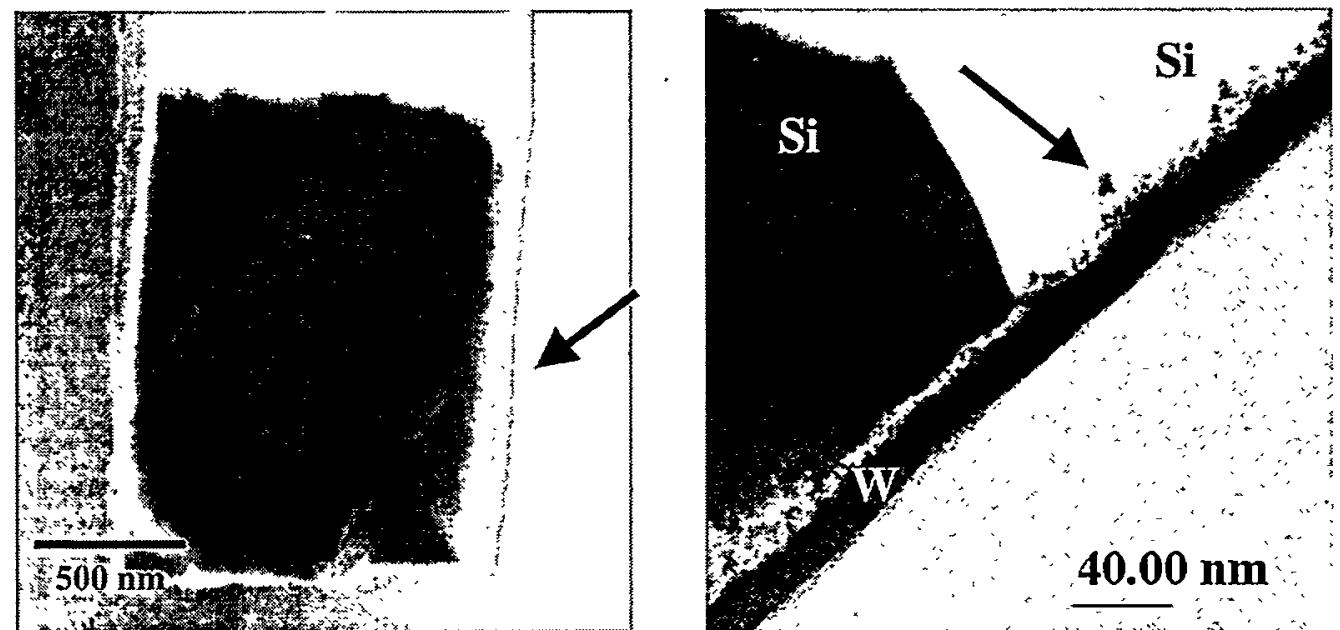

Figure 7. W coated polysilicon samples (a) fracture surface with crack initiation marked (b) TEM cross section showing "worm-holes" at W-polysilicon interface.

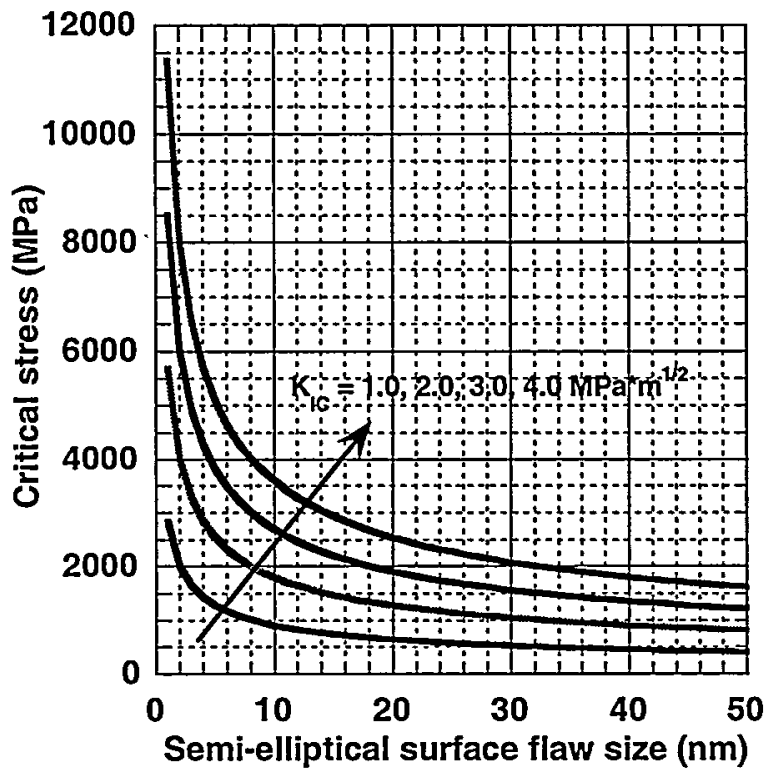

Figure 7. Sensitivity plot of the critical stress for semi-elliptical surface flaws. 


\section{REFERENCES}

1. Koskinen, J., J. E. Steinwall, R. Soave, H. H. Johnson, J. Micromechanics and Microengineering, 3, pp. 13-17, (1993).

2. Brown, S.B., G. Povirk, and J. Connally in Micro Electro Mechanical Systems - MEMS, (IEEE Proc. Piscataway, NJ 1993) pp. 99-104.

3. Read, D.T. and J.C. Marshall in Microlithography and Metrology in Micromachining II (SPIE Proc. 2880, 1996) pp. 56-63.

4. Yuan, B., Ph.D. Dissertation, Johns Hopkins University, Baltimore, MD. (1997)

5. Tsuchiya, T., O. Tabata, J. Sakata, Y. Taga in Tenth Annual International Workshop on Micro Electro Mechanical Systems (IEEE Proc. New York, NY) pp. 529-534.

6. Sharpe, W.N.J., K.T. Turner, and R. Edwards, Experimental Mechanics, 39, pp. 162-170, (1999)

7. Greek, S. and S. Johansson in Micromachined Devices and Components III (SPIE Proc. 3224, 1997) pp. 344-351.

8. Weibull, W. in Proceedings Royal Swedish Institute for Engineering Research, (151, 1939) pp. 1-45.

9. Sullivan, J.D. and P.H. Lauzon, J. Materials Science Letters, 5, pp. 1245-1247 (1986).

10. Mani, S.S., J.G. Fleming, and J.J. Sniegowski in Micromachining and Microfabrication Process Technology V (SPIE Proc 3874, 1999), pp. 150-157.

11. Mani, S.S., J.G. Fleming, J.J. Sniegowski, M.P. de Boer in Materials Science of Microelectromechanical Systems (MEMS) II. (MRS Proc. 1999). submitted.

12. LaVan, D.A., T.E. Buchheit, and M. Nowell in Materials Science of Microelectromechanical Systems (MEMS) Devices II, (MRS Proc. 1999). submitted.

13. Simmons, G. and H. Wang, Single Crystal Elastic Constants and Calculated Aggregate Properties. 2nd ed., The MIT Press, Cambridge, 1971.

14. Voigt, W., Lehrbuch der Kristallphysik, B. G. Teubner, Leipzig, 1910.

15. Reuss, A. in Z. Angew. Math, 9, pp. 49-58, 1928.

16. For a semielliptical surface flaw $(\mathrm{a}=\mathrm{c})$ in a flat plate subject to uniform tension evaluated at $\varphi=90$.

17. Anderson, T.L., Fracture Mechanics, 2nd ed., CRC Press, Boca Raton, FL 1995. 